\title{
Matchmaking Promotes Happiness
}

\section{Citation}

Anik, Lalin, and Michael I. Norton. "Matchmaking Promotes Happiness." Social Psychological \& Personality Science (forthcoming).

\section{Permanent link}

http://nrs.harvard.edu/urn-3:HUL.InstRepos:12534912

\section{Terms of Use}

This article was downloaded from Harvard University's DASH repository, and is made available under the terms and conditions applicable to Open Access Policy Articles, as set forth at http:// nrs.harvard.edu/urn-3:HUL.InstRepos:dash.current.terms-of-use\#OAP

\section{Share Your Story}

The Harvard community has made this article openly available.

Please share how this access benefits you. Submit a story.

Accessibility 
RUNNING HEAD: Matchmaking Promotes Happiness

Matchmaking Promotes Happiness

\author{
Lalin Anik \\ Duke University
}

Michael I. Norton

Harvard Business School 


\begin{abstract}
Four studies document and explore the psychology underlying people's proclivity to connect people to each other - to play "matchmaker." First, Study 1 shows that chronic matchmaking is associated with higher well-being. Studies 2 and 3 show that matching others on the basis of how well they will get along leads to a greater increase in happiness and is more intrinsically rewarding than other tasks (e.g., deciding which people would not get along). Study 4 investigates a moderator of the rewarding nature of matchmaking: the type of connection. We show that bridging ties are relatively more attractive than bonding ties: the more unlikely the match, the more rewarding it is. Taken together, these studies provide correlational and causal evidence for the role of matchmaking in promoting happiness.
\end{abstract}




\section{Matchmaking Promotes Happiness}

At some point, most people have made matches between others, from grabbing two strangers by the arm at a party and introducing them to each other to brokering romantic connections. Indeed, social networking websites such as Facebook and LinkedIn increasingly make brokering such introductions as effortless as a few clicks of a mouse. Or, if not matchmakers themselves, many people can think of a friend or acquaintance notorious for their efforts to make such introductions - even if sometimes awkwardly unsuccessful. In fact, people often err on the side of "overintroduction," checking to make sure that two people know each other only to find that the two are already acquainted. Despite its ubiquity, the psychological drivers of such matchmaking have received little attention, with some perspectives suggesting that matchmaking has negative costs to the matchmaker. We investigate the proclivity to make matches between others, demonstrating that such matchmaking - creating ties between others is both intrinsically rewarding and pays in the form of increased well-being: encouraging people to become matchmakers by inducing them to connect people to each other has a causal impact on their happiness.

Certainly, a great deal of evidence suggests that people enjoy connecting themselves to others and that having such social connections is strongly associated with well-being. Humans spend some $80 \%$ of their waking hours in the company of others (Emler, 1994; Kahneman, Krueger, Schkade, Schwarz, \& Stone, 2004), such that their dual needs of being alone and belonging often tip towards the latter (Aronson, 1988; Baumeister \& Leary, 1995). Moreover, having connections with others is associated with better objective and subjective well-being (Myers, 1999). Having more discrete types of social relationships is associated with increased longevity (Berkman, 1995) and better physical health outcomes (Berkman et al., 2000; Cohen, 
1988; House et al., 1988; Seeman, 1996; Uchino, 2004). Social relationships not only impact objective but also subjective well-being (Andrews et al., 1978; Henderson, 1980; Miller \& Ingham, 1976), such that having a rich network of close family and friends correlates with psychological well-being (Diener \& Seligman, 2002; Fleeson, Malanos, \& Achille, 2002). Matchmaking and Happiness

The above research clearly demonstrates the positive impact ties between the self and others have on well-being, but the possibility that initiating connections between others might also impact well-being remain unexplored. In short, we explore the emotional benefits of making matches not between oneself and others, but between two other people. We note that matchmaking takes many forms, from romantic matchmaking (e.g., connecting partners for dates) to social matchmaking (e.g., introducing friends and acquaintances) to professional matchmaking (e.g., linking two colleagues). Though the term "matchmaking" is most commonly associated with romantic efforts, we use the term to refer to a broad category of connections to explore the general emotional benefits of matchmaking.

Why might people find matchmaking rewarding? Existing research suggests that the benefits of matchmaking may arise due to a variety of motivations. First, matchmaking may allow the matchmaker to send positive signals to the self and others. Introducing unacquainted individuals may allow matchmakers to signal positive traits such as social acumen and intelligence to themselves (Bem 1972; Bodner \& Prelec, 2003). But people also engage in public displays - such as conspicuous consumption - to signal their status and power to others (Becker 1974; Glazer \& Konrad, 1996; Griskevicius et al. 2007); being the person who brings others together may signal one's status in the social network. Indeed, connecting two people who form a lasting partnership - whether romantic, platonic, or professional - may put those individuals in 
the matchmakers' debt, leading them to reciprocate in the future (Cialdini, 1993). Relatedly, matchmaking may signal that the matchmaker is a helpful person, which may increase others' likelihood of behaving generously to the matchmaker; indeed, matchmaking increases the density of social networks, which has been shown to facilitate trust and cooperation (Coleman, 1990; Ibarra, 1992). In addition to these somewhat self-interested benefits of matchmaking, matchmakers may also have altruistic motivations: to increase the happiness and well-being of others. The act of connecting two lonely people, for example, might be driven by a desire to increase their happiness; altruistic behaviors have been shown to have emotional benefits for both givers and receivers (Dunn, Aknin, \& Norton, 2008). Thus given the variety of research supporting a possible link between matchmaking and well-being, we suggest that matchmaking may promote happiness.

\section{Overview}

We first explore whether chronic matchmakers - those who habitually connect others in their everyday lives - have higher well-being (Study 1). Next, we measure the benefits of matchmaking in two ways, by both assessing people's happiness before and after they engage in matchmaking (Study 2) and examining people's intrinsic willingness to persist at creating connections between others (Study 3). We pit the rewarding nature of matchmaking against another kind of reward - money - and explore whether paying people to make matches between others "crowds out" their inherent desire to create connections (Study 3). Finally, Study 4 investigates a moderator of the rewarding nature of matchmaking: the type of connection.

\section{Study 1: Matchmaking Correlates with Well-Being}

Study 1 offers an initial examination of the relationship between chronic matchmaking and overall well-being. In addition, because chronic matchmakers may also have larger social 
networks, in and of itself a predictor of well-being (Burt, 1987; Chan \& Lee, 2006), we examine the link between matchmaking and well-being while controlling for network size. Since matchmakers may have personality traits (e.g., extraversion) that correlate with well-being (DeNeve \& Cooper, 1998), we also control for personality traits. In an online survey, participants rated their propensity to make matches between others and their perceived success at matchmaking, reported their total number of acquaintances and friends, and completed wellvalidated scales assessing subjective well-being and personality.

Method

A sample of 301 participants ( $32 \%$ female; $\left.M_{\mathrm{age}}=29.1, S D=9.2\right)$ were recruited on Amazon's Mechanical Turk services for a 5-minute study on social interactions, and were paid $\$ .25$.

Respondents rated their propensity to make matches between others and their perceived success at matchmaking. We used four items to assess people's propensity to make matches between others: I introduce my acquaintances to each other; I introduce my friends to each other; I set up my friends on dates; I am a resource for people around me to find social and professional connections (Cronbach's $\alpha=.81$ ). These items were rated on a 4-point scale (1: not at all true of me to 4: very true of me). We used four items to assess their perceived success at making connections: How good are you at connecting your friends with each other? How good are you at connecting your acquaintances with each other? How good are you at setting up your friends on dates? What percent of these dates are successful? (Cronbach's $\alpha=.85$ ). The first three items were rated on a 10-point scale (1: not at all good at it to 10: extremely good at it), and participants provided open ended responses to the percentage question; we standardized these items to create the composite measure. 
Respondents also reported their total number of acquaintances and total number of friends, and completed Diener, Emmons, Larsen, and Griffin's (1985) well-being scale (Cronbach's $\alpha=.85$ ). Finally, participants completed the ten-item personality inventory (TIPI; Gosling, Rentfrow, \& Swann, 2003), which contains two items measuring each of the Big Five personality dimensions (extraversion, agreeableness, conscientiousness, emotional stability and openness to experiences). Using a 7-point scale (1: disagree strongly to 7: agree strongly), participants rated the extent to which they felt each of the five traits applied to them.

Results

Both propensity to make matches and perceived success at matchmaking were positively correlated with well-being, $r s=.36$ and $.37, p s<.001$. Interestingly, the seven individual items for each scale (four for propensity, three for perceived success) displayed striking consistency in their correlation with well-being, $.24<r s<.35$, all $p s<.001$. Thus despite the different types of matchmaking assessed - from setting up friends on dates $(r=.28)$ to introducing friends to each other $(r=.31)$ - matchmaking appears to have a consistent positive relationship with well-being.

Number of acquaintances and number of friends were each correlated with propensity, $r s=.13$ and $.12, p s<.04$, and perceived success, $r s=.15$ and $.14, p s<.02$. However, when we controlled for number of friends and acquaintances, the relationships between well-being and both propensity and perceived success remained significant, $\beta s=.36$ and $.37, p s<.001$. Moreover, when we controlled for the five personality dimensions in regressions predicting well-being, the relationships between well-being and both propensity and perceived success also remained significant, $\beta s=.25$ and $.24, p s<.001$. In the regressions for both propensity and perceived success, emotional stability predicted well-being, $p s<.001$; extraversion was a significant 
predictor in the former analysis, $p<.05$, and marginally significant in the latter, $p=.055$; no other factors emerged as significant predictors in either analysis, $p s>.07$.

While we replicated previous findings that extraversion and emotional stability are both positively related to well-being, we demonstrate a significant relationship between propensity to make matches and perceived success at matchmaking when controlling for these and other personality variables, and when controlling for the size of participants' social networks. These results provide preliminary correlational evidence that chronic matchmakers are happier with their lives, over and above any effect of the size of their networks or their personality traits.

Study 2: Matchmaking in the Laboratory

In Study 2, we tested the causal impact of matchmaking on happiness in a laboratory setting by assigning people to match individuals to each other and measuring their happiness before and after the matching task. In addition, we investigated whether the type of match matters by randomly assigning people to one of three tasks: making matches on the basis of who would get along well (the match condition), who would get along poorly (mismatch), and who had the most similar social security numbers (random). We included the random condition to examine whether matchmaking based on any similarity would increase happiness or whether the emotional benefits of matchmaking are specific to meaningful connections. We included both the match and mismatch conditions because each required participants to think about social relationships between others, which may have been interesting in its own right. We expected, however, that matching people with the goal of creating connections (match) would lead to greater happiness than matching on other dimensions (mismatch or random).

\section{Method}


Participants $\left(N=118 ; 61 \%\right.$ female, $\left.M_{\text {age }}=22.5, S D=4.4\right)$ were recruited from the subject pool of a university in the northeastern United States for a study about "the sharing of daily experience" that paid \$12. Participants completed the study in groups of six; two participants did not show such that our final sample consisted of 18 groups of six and two groups of five participants.

Participants first reported their happiness by marking a $17 \mathrm{~cm}$ line with endpoints not at all happy and very happy (Morewedge, Gilbert, Keysar, Berkovits, \& Wilson, 2007). Next, all participants were seated in a circle and introduced themselves to each other by stating their name, place of birth, occupation, and hobbies; we included this "warm up" task to give them some basis for making connections between their session-mates. After completing the "warm up" task, participants were informed that they would be making matches between others in the room, and each group was randomly assigned to one of three tasks. In the match condition, participants were asked to match pairs of people who they thought would get along well; those in the mismatch condition were asked to match pairs who they thought would not get along well; those in the random condition were asked to match pairs who they thought had the most similar last two digits of their social security numbers. In order to increase involvement in the matching task, participants were informed that the pairs they selected would interact in the next part of the study.

Next, participants again completed the same happiness measure. Based on the matches made by participants, three pairs were selected to move to a separate room for a 5-minute interaction in which they told each other more about themselves. Finally, participants were debriefed and compensated.

Results 
Participants were nested in groups which were in turn nested within the three conditions. Therefore, we conducted a 3 (condition: match, mismatch, random) X 2 (time of measurement: pre task, post task) mixed effects model with random factors for participants, groups, and the groups by time of measurement interaction, which revealed the predicted significant interaction between condition and time of measurement, $F(2,115)=6.22, p=.003, \eta_{p}{ }^{2}=.10$. As our account suggests, contrasts revealed that participants in the match condition experienced a significant increase in pre-matching $(M=10.49, S D=2.57)$ to post-matching happiness $(M=11.16, S D=2.29)$, $t(115)=3.10, p=.003$. If anything, happiness declined in both the mismatch $(M s=10.97$ and 10.53, $S D s=3.34$ and 3.29) and random conditions $(M s=11.86$ and 11.60, SDs=2.73 and 2.46), although these differences were not significant, $p s>.11$. Further contrasts showed that the boost in happiness in the match condition was significantly greater than the decrease in happiness in both the mismatch and random conditions, $p s<.004{ }^{1}$

In sum, Study 2 offers initial evidence that assigning people to matchmaking increases their happiness - but only when that matching is done in the service of creating connections between others.

Study 3: Matchmaking is Intrinsically Rewarding

In Study 3, we assessed the benefits of matchmaking between others using a different methodology: Rather than measuring happiness directly, we measured the intrinsic reward of matchmaking by examining people's persistence on one of two tasks: matching which of three people a target individual would either get along with best (match) or looks most like (appearance).

We also varied whether participants completed each trial of the task for free, for $1 \varnothing$, or for $2 \phi$, a design that allowed us to document the intrinsic reward of matchmaking in two ways. 
First, we expected that participants would be willing to complete more trials of the match task than the appearance, providing evidence for greater intrinsic reward of the former task. Second, while we expected that higher pay per trial would increase the number of trials that participants completed of the of the less-intrinsically-rewarding appearance task, we explored whether paying participants for the intrinsically rewarding match task might actually undermine their motivation and lead them to complete fewer trials. Research shows that providing extrinsic rewards - such as monetary incentives - for completing intrinsically satisfying tasks are not only ineffective but can be detrimental, "crowding out" people's motivation to perform those tasks (Deci, 1975; Lepper, Greene, \& Nisbett, 1973). As a result, we predicted that providing extrinsic monetary rewards for the intrinsically-rewarding match task would diminish participants' motivation to complete this task.

\section{Method}

Participants $\left(N=168,54 \%\right.$ female, $\left.M_{\text {age }}=21.6, S D=3.8\right)$ were recruited from the subject pool of a university in the northeastern United States for a 60-minute session that involved completing a series of unrelated studies that paid $\$ 15$.

Upon starting the task, participants were informed that they would be completing fifty trials of computer tasks and could choose how to split these fifty trials between two tasks. In the first task, participants were shown a photo of a target individual and asked to match the target with one of three potential matches (see Figure 1 for an example of the task). Participants were randomly assigned to one cell of a 2 (condition: match, appearance) X 3 (incentives: free, 1ф, $2 \phi$ ) design. Participants were either asked to select the person with whom the target would get along best (match) or the person who was most physically similar to the target (appearance); in addition, they either completed the task without incentives (free), or were told they would 
receive either $1 \phi$ or $2 \phi$ for each trial. After each trial, they were given the choice to complete another trial of this task or switch to work on a second task. The second (letter) task - designed to be boring - consisted of finding a target letter in a pull-down menu of four letters.

Participants were instructed that they would begin with the first task (match or appearance) and could complete all fifty trials of that task or move on to the letter task whenever they wished. After completing a practice trial of each task, they began with the match or appearance task. Our dependent variable was the number of trials completed in the first task (match or appearance) before switching to the letter task.

Results

Pretest. We pretested task enjoyment with a separate group of participants $(N=103$, $58.4 \%$ female, $\left.M_{\mathrm{age}}=34.4, S D=11.8\right)$ who completed one trial of each task ( match, appearance, letter) and rated them on enjoyment on a 7-point scale (1: not at all to 7: very much). Ratings of the matching task $(M=4.21, S D=1.70)$ and appearance task $(M=4.25, S D=1.64)$ did not differ, $F(1,102)=.05, p=.83$; as expected, both received higher ratings than the letter task $(M=2.42$, $S D=1.69), F s>80.00, p s<.001$.

Number of trials. A 2 (condition: match, appearance) X 3 (incentives: free, $1 \phi, 2 \phi$ ) ANOVA revealed no main effect of condition, $F(1,161)=2.50, p=.12$, or incentives, $F(2$, $161)=.86, p=.47$, but did reveal the predicted interaction, $F(2,161)=5.11, p<.01, \eta_{p}{ }^{2}=.10($ Figure 2). First, as expected, participants in the free conditions completed more than twice as many trials of the match task $(M=31.10, S D=20.25)$ than the appearance task $(M=14.82, S D=15.34)$, $t(57)=3.45, p<.001, d=.90$, suggesting that connecting others in terms of liking is intrinsically more rewarding than connecting others for physical similarity. 
Our second means of demonstrating intrinsic liking for the match task was to examine how additional monetary incentives would differentially impact people's desire to complete additional trials of both the appearance and match task. As expected, incentives increased the number of trials participants chose to complete of the appearance task, in a significant linear trend from free to $1 \phi$ to $2 \phi(M s=14.82,17.07$, and $26.27, S D s=15.33,17.49$, and 21.45), $t(82)=2.37, p=.02$. In contrast, providing incentives for the match task resulted in a significantly decreased willingness to complete trials both for participants in the $1 \not$ and $2 \phi$ conditions $(M \mathrm{~s}=20.25$ and 20.18, SDs $=18.53$ and 19.40) compared to those in the free condition $(M=31.10$, $S D=20.24$ ), $t s>2.04, p s<.05$ (Figure 2). These results suggest that while payment increased motivation for the less intrinsically appealing appearance task, incentives crowded out motivation for the more intrinsically appealing match task - such that paying more led to completing fewer trials.

Indeed, one final piece of evidence speaks to the inherently rewarding nature of the match task: we needed to pay $2 \varnothing$ per trial for the appearance task in order to induce people to complete even close to as many trials as they were willing to complete of the match task for free.

One possible explanation for our results is that happiness from matchmaking is due merely to having completed a task successfully. We conducted an additional study in which we both controlled for successful completion of the task and measured subjective feelings of success. Participants $\left(N=121,58 \%\right.$ female, $\left.M_{\text {age }}=33.6, S D=11.7\right)$ completed a similar computer paradigm as in Study 3, with two changes. In order to control for the successful completion of the task, all participants were assigned to complete 10 trials. And rather than two conditions, they were assigned to one of three conditions: matching which of three people a target individual would either get along with best (match) or least (mismatch), or which the target resembled most 
(appearance). Participants rated their happiness before and after the task on a 7-point scale (1: very unhappy to 7: very happy) as well as how successful they thought they were at making these matches on a 7-point scale (1: very unsuccessful to 7: very successful). A 3 (condition: match, mismatch, appearance) X 2 (time of measurement: pre task, post task) ANOVA revealed the predicted interaction between condition and time, $F(2,118)=5.83, p=.004, \eta_{p}{ }^{2}=.09$. Replicating our previous results, participants in the match condition experienced a significant increase from pre-matching $(M=5.19, S D=1.18)$ to post-matching happiness $(M=5.36, S D=1.11), t(42)=2.47$, $p=.02$. Happiness declined in both the mismatch $(M s=5.02$ and 4.76, SDs=.95 and 1.26) and appearance conditions $(M s=5.36$ and 5.08, $S D s=1.07$ and 1.05), and these differences were significant, $p s<.04$. However, a one-way ANOVA revealed no differences between participants’ perceived success at the different tasks, $F(2,118)=1.91, p=.15$. These results suggest that matchmaking itself - and not merely the successful completion of tasks - is uniquely rewarding.

Study 4: What Kinds of Matches Are Most Rewarding?

In Study 3, we explored a moderating factor of the impact of matchmaking on happiness: the type of connection. We posited that one reason that people find matchmaking rewarding is because it creates novel connections that increase network density. If this is the case, then creating matches between people who are unlikely to know each other should prove more rewarding than creating matches between people who are likely to know each other, because the former matches have more potential to increase network density (Gittell \& Vidal, 1998). Bridging ties, which connect people who previously did not know each other, offer rare and more novel opportunities for creating social capital at the level of the group; bonding ties, on the other hand, offer fewer benefits to the group as they primarily connect people who already have ties in common. We operationalized bridging and bonding ties by varying the gender and race of 
the people being matched; research suggests that similar people are more likely to interact than dissimilar people, such that creating a connection between members of different groups (e.g., a White male with an Asian female) is more likely to be a bridging tie than a connection made between members of the same group (e.g., two White males; McPherson, Smith-Lovin \& Cook, 2001).

Using several versions of the match task from the previous studies, we explored whether creating bridging ties - connecting people who were less likely to be acquainted - would be more rewarding than creating bonding ties.

\section{Method}

Participants $\left(N=132,49 \%\right.$ female, $\left.M_{\mathrm{age}}=21.1, S D=3.6\right)$ were recruited from the subject pool of a university in the northeastern United States for a 90-minute session that involved completing a series of unrelated studies that paid $\$ 20$.

As in Study 3, participants completed fifty trials of two tasks: the matching task or boring letter task; also as in Study 3, they could choose to complete as many trials of each task as they chose. All participants completed a version of the match task from the previous study, but were randomly assigned to one of eight different versions. In each version, the target individual was always either a Caucasian male or a Caucasian female; to manipulate the likelihood that the target individual would know the two possible matches, we varied the gender and race of the two matches - Caucasian males, Caucasian females, Asian males, or Asian females. We collapsed these eight versions into three levels of ties - same race and same gender versions (bonding ties), different gender and different race versions (bridging ties), or same race and different gender or different gender and same race versions (medium ties) (See Figure 3 for examples of ties).

\section{Results}


Pretest. We pretested these combinations to ensure that they successfully manipulated tie level. In a within-subjects design, a separate group of participants $(N=116,47 \%$ female, $\left.M_{\text {age }}=29.2, \mathrm{SD}=9.1\right)$ were shown fifty trials including examples from the eight different versions. They rated the likelihood that the target person would know one of the two people below on a 7point scale (1: extremely unlikely to 7: extremely likely). Bonding ties were rated as having a higher likelihood of knowing each other $(M=4.78, S D=.94)$ than both medium ties $(M=4.07$, $S D=.86)$ and bridging ties $(M=3.52, S D=.95), F(2,931)=118.69, p<.001$; all three ratings were significantly different from each other, all $t s>7.68$, all $p s<.001$.

Number of trials. Type of tie impacted the number of matching trials completed, $F(2$, $128)=2.85, p<.05$. The linear trend was significant, $t(129)=2.92, p<.01)$, such that participants completed the greatest number of trials in the matching task when matching across bridging ties $(M=25.03, S D=18.22)$ followed by medium ties $(M=19.64, S D=15.73)$ followed by bonding ties $(M=13.28, S D=13.98)$; indeed, participants in the bridging ties condition completed nearly twice as many trials as those in the bonding ties condition, $t(61)=2.88, p<.01 .^{2}$

By definition, bridging ties involved matching people of the same gender whereas bonding ties involved matching people of different genders. If participants made the assumption that the target individuals were heterosexual, it is possible that bonding ties were more rewarding than bridging ties because they involved romantic matchmaking. However, an examination of the different types of medium ties suggests that opposite-gender pairings do not differ from samegender pairings: Caucasian Female with Caucasian Males $(M=18.18)$, Caucasian Female with Asian Females $(M=19.25)$, Caucasian Male with Asian Males $(M=19.44)$, and Caucasian Male with Caucasian Females $(M=21.88), t s<.70, p s>.49$. Thus as in Study 1 - in which making 
romantic and platonic connections were similarly correlated with well-being - these results offer evidence for the benefits of many types of matchmaking.

\section{General Discussion}

Taken together, these studies provided evidence for our proposed link between matchmaking and happiness. Inducing people to make matches between strangers increased happiness in the moment, and people found a task that involved matching others based on their beliefs about their likely rapport to be more intrinsically rewarding than tasks that involved other types of matching. We documented a critical moderator of rewarding nature of matchmaking: creating bridging ties - connecting people who would not otherwise be acquainted - is more rewarding than bonding ties.

Our laboratory studies are, of course, proxies for the kinds of real-world matchmaking in which people engage every day. The fact that this kind of minimalistic matchmaking continues to provide rewards parallels other research suggesting that minimalistic laboratory paradigms for example, simulating gossip and altruistic punishment (Fehr \& Gächter, 2002; Feinberg et al., 2012) - can prove fruitful in shedding light into the everyday emotional consequences of

behavior. Importantly, our results demonstrating the emotional benefits of chronic matchmaking further support the notion that matchmaking proves rewarding beyond the laboratory setting. At the same time, investigations that extend our results into everyday settings will offer further insight into the psychology of matchmaking. For example, a daily diary methodology could be used to examine whether people are happier on days when they connect others, while online social networks such as Facebook and LinkedIn offer readily-available opportunities to assess both platonic and professional matchmaking. 
Our results offer several directions for future research. First, it would be worthwhile to examine whether matchmaking is driven by altruistic or selfish reasons - or a combination of two. Are matchmakers still happy if they make an introduction between two others who leave and interact without them? Relatedly, assessing people's preference for public vs. anonymous matches would test whether social signaling is a driver of matchmaking: people preferring to be recognized for their matches - by the matched pair or observers - would offer evidence that matchmaking is not driven by purely altruistic motivations.

We note that our results stand in seeming contrast to social network research suggesting that matchmaking can come with costs. Burt (2001) posits that social networks are like a market in which some people achieve more prominent places; the benefits to actors with prominent places in the network depend critically on the type of network. Networks with structural holes (where there are missing links between network members), allow some individuals to have more access to resources than others (Coleman, 1990). These brokers are strategically located between others and derive power from refusing to connect others in order to maintain their standing; in this view, matchmaking could have a negative impact as an introduction would come with the cost of the matchmaker's structural advantage (Burt, 1998; Simmel, 1955). Our studies show that closing gaps in social networks by forming ties between others has benefits for the matchmaker in the form of increased happiness. Future research can pit the positive benefits of matchmaking against the benefits of being a broker in a network to examine whether people would engage in matchmaking even when it is costly to do so.

We document a novel means by which people can increase their happiness: as with other behaviors such as spending money on others (Dunn et al., 2008) and performing random acts of kindness (Lyubomirsky, Sheldon, \& Schkade, 2005), successful matchmaking promotes 
happiness in matchmakers. Also, like these other behaviors, matchmaking is easy to implement: unlike other behaviors which increase happiness, such as exercise and becoming more religious (Mochon, Norton, \& Ariely, 2008), matchmaking doesn't require a great deal of time and effort, but only introducing two people already in one's social network. Indeed, as noted earlier, websites such as Facebook and LinkedIn make matchmaking as accessible as sending a quick email. Moreover, creating successful matches between others also can have additional benefits that extend beyond the matchmaker to the two newly-acquainted individuals, from providing them with opportunities for employment (Granovetter, 1973) to increasing their social support. Even more broadly, matchmaking increases the density of social networks - more people know more people in common - and this kind of social capital is associated with a range of positive group-level outcomes including lower crime rates and improved public health (Putnam, 2001). As a result, the benefits of matchmaking may extend beyond the matchmakers to the matched dyads and to the wider community. 


\section{References}

Andrews, G., Tennant, C., Hewson, D. M., \& Vaillant, G. E. (1978). Life event stress, social support, coping style, and risk of psychological impairment. The Journal of Nervous and Mental Disease, 166(5), 307-316.

Aronson, E. (1988). The social animal (5 ${ }^{\text {th }}$ ed.). New York: Freeman.

Baumeister, R. F., \& Leary, M. R. (1995). The need to belong: Desire for interpersonal attachments as a fundamental human motivation. Psychological Bulletin, 117(3), 497529.

Becker, G. S. (1974). Theory of social interaction. Journal of Political Economy, 82, 1064-1093.

Bem D. J. (1972). Self-perception theory. In L. Berkowitz (Ed.), Advances in Experimental Social Psychology (Vol. 6). New York: Academic Press, 1-62.

Bodner, R., \& Prelec, D. (2003). The diagnostic value of actions in a self-signaling model. The Psychology of Economic Decisions, 1, 105-23.

Berkman, L. F. (1995). The role of social relations in health promotion. Psychosomatic Medicine, 57(3), 245-254.

Berkman, L. F., Glass, T., Brissette, I., \& Seeman, T. E. (2000). From social integration to health: Durkheim in the new millennium. Social Science and Medicine, 51(6), 843-857.

Burt, R. S. (1987). A note on strangers, friends and happiness. Social Networks, 9, 311-33.

Burt, R. S. (1998). The gender of social capital. Rationality and Society, 10, 5-46.

Burt, R. S. (2001). Structural holes versus network closure as social capital. Social Capital: Theory and research, 31-56.

Chan, Y., \& Lee, R. (2006). Network size, social support and happiness in later life: A comparative study of Beijing and Hong Kong. Journal of Happiness Studies, 7, 87-112. 
Cialdini, R.B. (1993). Influence: The psychology of persuasion. New York: Morrow

Cohen S. (1988). Psychosocial models of social support in the etiology of physical disease. Health Psychology, 7, 269-297.

Coleman, J. S. (1990). Foundations of social theory. Cambridge: Harvard University Press.

Deci, E. L. (1975). Intrinsic motivation. New York: Plenum.

DeNeve, K. M., \& Cooper, H. (1998). The happy personality: A meta-analysis of 137 personality traits and subjective well-being. Psychological Bulletin, 124(2), 197.

Diener, E., Emmons, R. A., Larsen, R. J., \& Griffin, S. (1985). The satisfaction with life scale. Journal of Personality Assessment, 49, 71-75.

Diener, E., \& Seligman, M. E. (2002). Very happy people. Psychological Science, 13(1), 81-84.

Dunn, E.W., Aknin, L.B., \& Norton, M.I. (2008). Spending money on others promotes happiness. Science, 319, 1687-1688.

Emler, N. (1994). Gossip, reputation and adaptation. In Goodman, R.F., \& Ben-Ze'ev, A. (Eds.), Good gossip (pp. 34-46). Lawrence, KS: University of Kansas Press.

Fehr, E., \& Gächter, S. (2005). Human behaviour: Egalitarian motive and altruistic punishment (reply). Nature, 433(7021), E1-E2.

Feinberg, M., Willer, R., Stellar, J., \& Keltner, D. (2012). The virtues of gossip: Reputational information sharing as prosocial behavior. Journal of Personality and Social Psychology, 102(5), 1015-1030.

Fleeson, W., Malanos, A. B., \& Achille, N. M. (2002). An intraindividual process approach to the relationship between extraversion and positive affect: Is acting extraverted as" good" as being extraverted? Journal of Personality and Social Psychology, 83(6), 1409-1422. 
Gittell, R., \& Vidal, A. (1998). Community organizing: Building social capital as a development strategy. Thousand Oaks, CA: Sage.

Glazer, A., \& Konrad, K. A. (1996). A signaling explanation for charity. American Economic Review, 86, 1019-1028.

Gosling, S. D., Rentfrow, P. J., \& Swann Jr, W. B. (2003). A very brief measure of the Big-Five personality domains. Journal of Research in Personality, 37(6), 504-528.

Granovetter, M.S. (1973). The strength of weak ties. American Journal of Sociology, 78, 13601380.

Griskevicius, V., Tybur, J.M., Sundie, J.M., Cialdini, R.B., Miller, G.F., \& Kenrick, D.T. (2007). Blatant benevolence and conspicuous consumption: When romantic motives elicit strategic costly signals. Journal of Personality and Social Psychology, 93, 85-102.

Henderson, S. (1980). A development in social psychiatry the systematic study of social bonds. The Journal of Nervous and Mental Disease, 168(2), 63-69.

House, J. S., Landis, K. R., \& Umberson, D. (1988). Social relationships and health. Science, $241(4865), 540-545$.

Ibarra, H. (1992). Homophily and Differential Returns: Sex Differences in Network Structure and Access in an Advertising Firm. Administrative Science Quarterly, 37, 422-47.

Kahneman, D., Krueger, A. B., Schkade, D. A., Schwarz, N., \& Stone, A. A. (2004). A survey method for characterizing daily life experience: The day reconstruction method. Science, 306, 1776-1780.

Lepper, M. R., Greene, D., \& Nisbett, R. E. (1973). Undermining children's intrinsic interest with extrinsic reward: A test of the "overjustification" hypothesis. Journal of Personality and Social Psychology, 28, 129-137. 
Lyubomirsky, S., Sheldon, K. M., \& Schkade, D. (2005). Pursuing happiness: The architecture of sustainable change. Review of General Psychology, 9, 111-131.

McPherson, M., Smith-Lovin, L., \& Cook, J. M. (2001). Birds of a feather: Homophily in social networks. Annual Review of Sociology, 415-444.

Miller, P. M., \& Ingham, J. G. (1976). Friends, confidants and symptoms. Social Psychiatry, $11(2), 51-58$

Mochon, D., Norton, M. I., \& Ariely, D. (2008). Getting off the hedonic treadmill, one step at a time: The impact of regular religious practice and exercise on well-being. Journal of Economic Psychology, 29(5), 632-642.

Morewedge, C. K., Gilbert, D. T., Keysar, B., Berkovits, M. J., \& Wilson, T. D. (2007).

Mispredicting the hedonic benefits of segregated gains. Journal of Experimental Psychology: General, 136, 700-709.

Myers, D. G. (1999). Close relationships and quality of life. In D. Kahneman, E. Diener, \& N. Schwarz (Eds.), Well-being: The foundations of hedonic psychology (pp. 374-391). New York: Russell Sage Foundation.

Putnam, R. D. (2000). Bowling alone: The collapse and revival of American community, New York: Simon \& Schuster.

Seeman, T. E. (1996). Social ties and health. Annals of Epidemiology, 6, 442- 451.

Simmel, G. (1955). Conflict and the Web of Group Affiliations (trans. By Kurt H. Wolff and Reinhard Bendix). New York: Free Press.

Uchino, B.N. (2004). Social support and physical health. New Haven, CT: Yale University Press. 


\section{Footnotes}

1. A 3 (condition: match, mismatch, random) X 2 (happiness: pre-task, post-task) X 2 (gender: male or female) ANOVA revealed no main effect of gender or interactions with gender, all $F \mathrm{~s}<.72$, all $p \mathrm{~s}>.49$. Similarly, including gender does not substantially change our results in Studies 2-4; we therefore do not report this variable further.

2. While we collapsed the eight versions into three conditions (bonding, medium, and bridging) for ease of presentation, results for the different forms that each type of tie took were similar. Bonding ties: Caucasian Female with Caucasian Females $(M=14.72, S D=16.05)$, and Caucasian Male with Caucasian Males $(M=11.43, S D=11.08)$; Medium ties: Caucasian Female with Asian Females $(M=19.25, S D=17.40)$, Caucasian Female with Caucasian Males $(M=18.18, S D=14.45)$, Caucasian Male with Asian Males $(M=19.44, S D=15.73)$, and Caucasian Male with Caucasian Females $(M=21.88, S D=16.14)$; Bridging ties: Caucasian Female with Asian Males $(M=25.41, S D=18.40)$, and Caucasian Male with Asian Females $(M=24.57, S D=18.69)$. 


\section{Figure 1}

Sample trial from the match condition (Study 3).

Who do you think would get along best with the focus person?

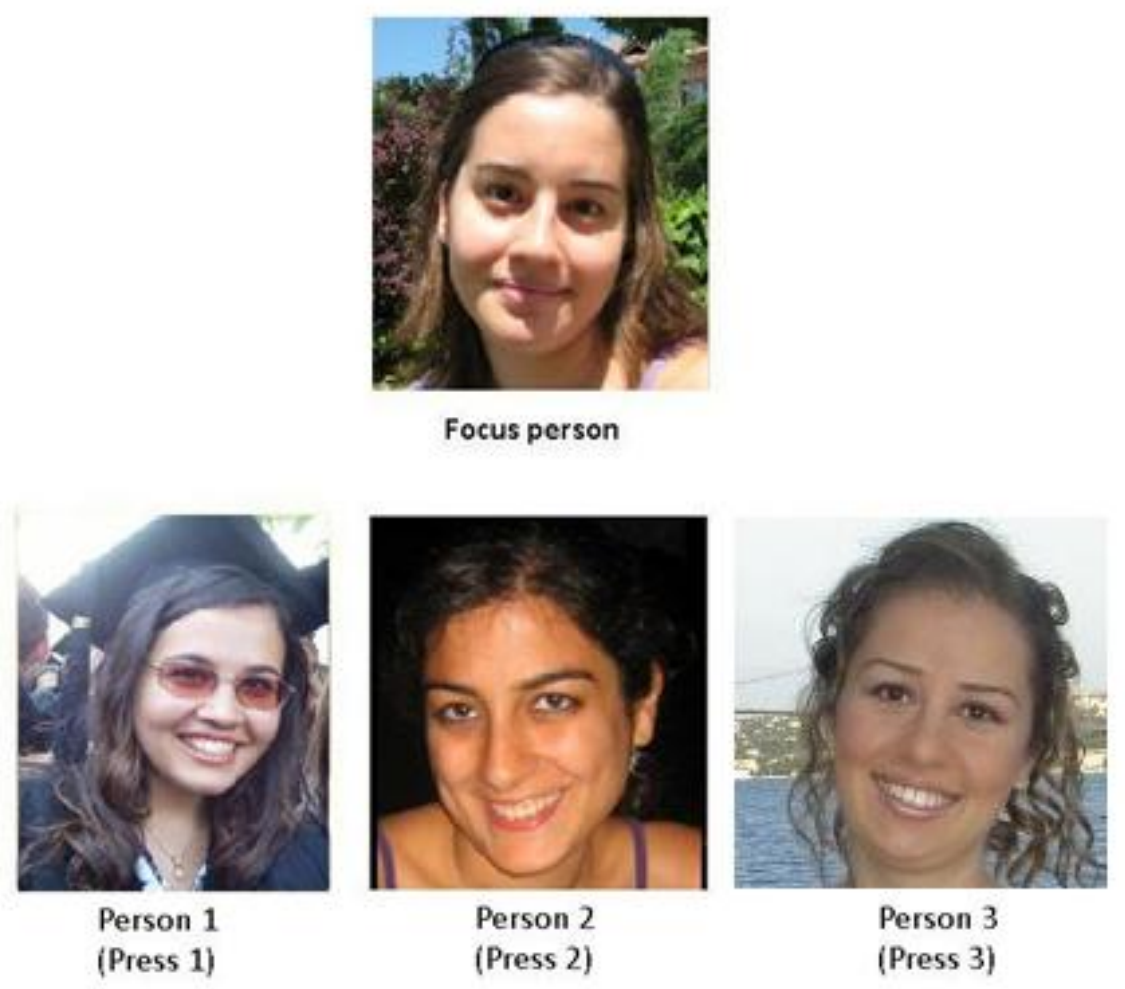


Figure 2

Incentives lead to an increase in number of trials completed in the appearance condition, but a decrease in the match condition (Study 3).

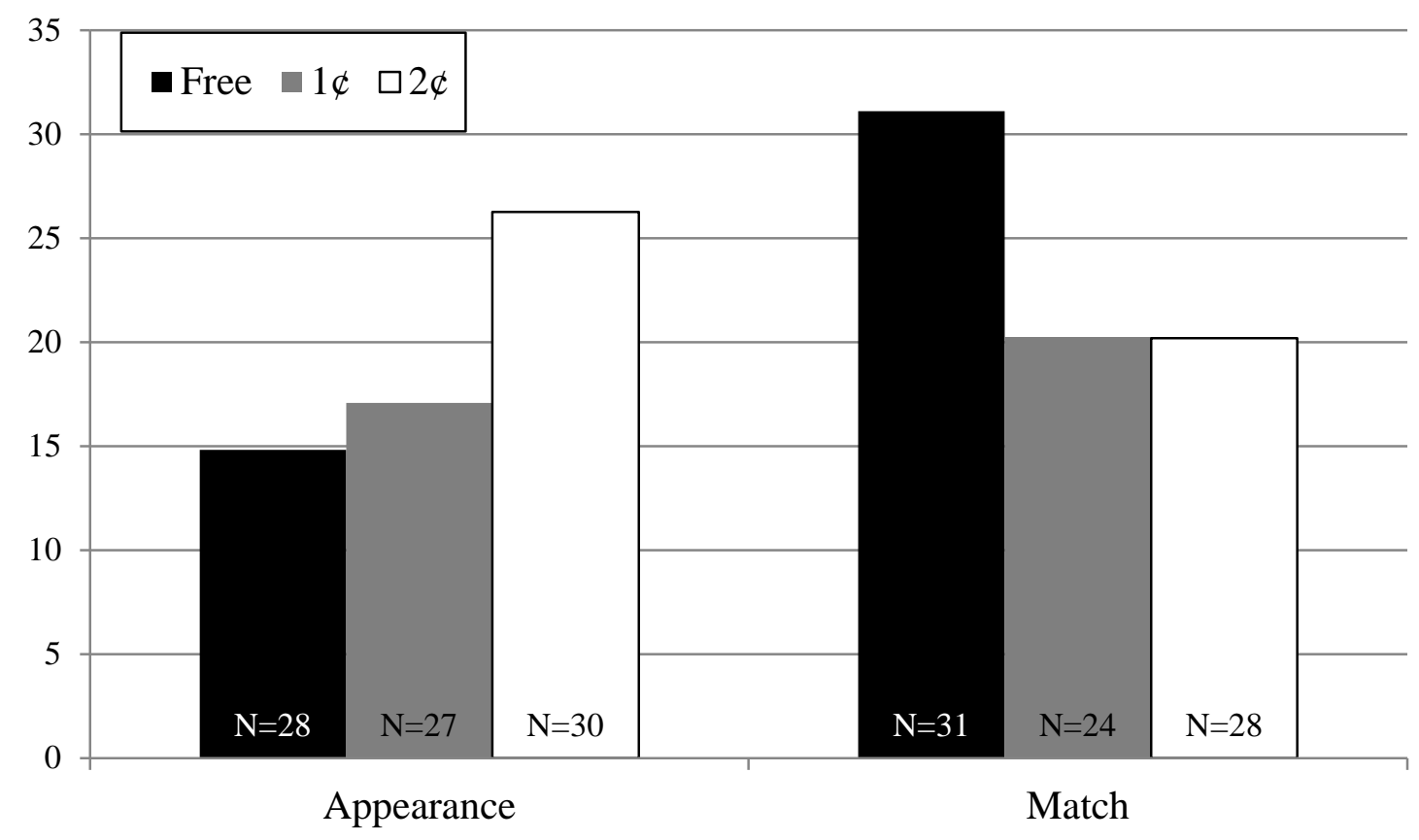


Figure 3

Example bonding tie: Caucasian female target with Caucasian female potential matches (A);

Example medium tie: Caucasian female target with Asian female potential matches (B); Example bridging tie: Caucasian female target with Asian male potential matches (C) (Study 4)
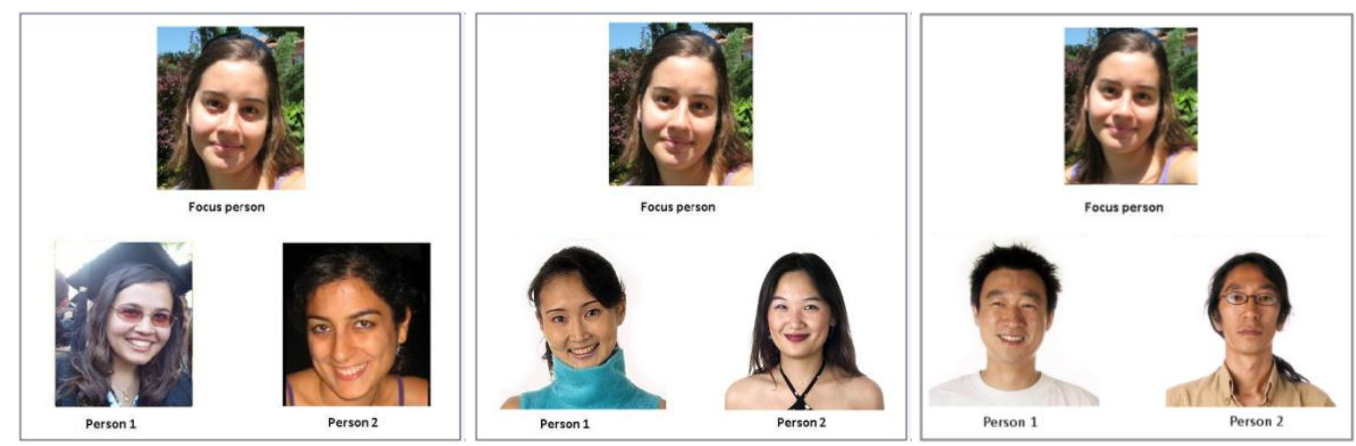

A

B

C 